\title{
Sensitivity analysis of peak and annual space cooling load at simplified office dynamic building model
}

\author{
Vasco Zeferina ${ }^{1, *}$, Christina Birch $^{1}$, Rodger Edwards ${ }^{1}$ and Ruth Wood $^{1}$ \\ ${ }^{1}$ School of Mechanical, Aerospace and Civil Engineering, Pariser building, Sackville Street, University of Manchester, M13 9PL, UK
}

\begin{abstract}
The focused investigation of building design is necessary to understand and quantify the implication of different design parameters on their energy performance. The design of future buildings is a major challenge, as current designs may be inappropriate in a future with global warming due to climate change impacts. In addition this understanding is necessary to be able to predict timing and profile of future energy demand, which is crucial for the long-term planning of energy infrastructures - particularly electricity. In this paper, the Morris Elementary Effects method is used as a screening method, to identify the key parameters of the design and operation of office buildings that affect the estimation of space cooling peak load and annual energy demand. Internal heat gains, cooling set-point and ventilation rates are identified as the parameters with larger implications for both annual and peak space cooling demand. In future climate scenarios, the magnitude of change of annual space cooling demand is significantly (around five times) larger than the change in the peak demand. Asides from the potential increase of space cooling demand in future scenarios, the sensitivity of the space cooling demand relative to the change in design parameters is potentially much larger.
\end{abstract}

\section{Introduction}

Mitigation and adaptation to Climate Change (CC) impacts will be one of the most important challenges of the twenty-first century. The UK Climate Projections produced in 2009 (UKCP09) estimate that the increase in maximum summer temperatures in the UK may be between 2 and $10^{\circ} \mathrm{C}$ by the $2080 \mathrm{~s}$ in comparison to the baseline period (1960-1990) [1]. Therefore, it is necessary to consider approaches to the mitigation of $\mathrm{CC}$ impacts and study the possible consequences in order to take informed and rational actions.

Current building designs may be inappropriate in the future, and indeed within the current UK building stock, there are concerns that overheating is occurring more frequently [2,3]. It has been predicted that this effect will be exacerbated by future CC. In particular, rising temperatures could lead to a substantial increase in cooling demand and cooling peak loads, namely due to an increase in Air Conditioning (AC) penetration and more intense demand from existing cooling systems [4].

Office buildings in the UK generally exhibit significant intense internal heat gains (IHG) (over 40 W. $\mathrm{m}^{-2}$ ) [5] and large floor space areas (over $1000 \mathrm{~m}^{2}$ ) [6], which leads to high cooling requirements. It is estimated that $65 \%$ of the total office floor space area in the UK is provided with mechanical cooling [6]. Furthermore, future climate projections suggest that there are risks that cooling demand and overheating intensity will increase significantly in office buildings in the UK $[3,7,8]$. Therefore, to thoroughly understand the extension of the effect on cooling demand of buildings due to $\mathrm{CC}$ impacts, it is necessary to evaluate the thermal performance of buildings using a vast and flexible set of parameters.

Dynamic building performance simulation permits comprehensive analysis of buildings' thermal performance, allowing detailed input characterisation of models, an extensive set of output variables and different time-scales of analysis. On the other hand, its complexity can exacerbate the uncertainty of the analysis, due to the requirement for extensive and accurate input model parameters.

The uncertainty on the energy performance of future buildings is the aggregation of different sources of uncertainties in model inputs and modelling scenarios $[9,10]$. Uncertainties result from possible discrepancies in the characterisation of occupancy, building envelopes and HVAC systems in future building stocks and the estimation of future weather conditions. In order to produce better estimations of future office buildings' energy performance, it is important to quantify the implication of each building system model component and boundary conditions, on the energy demand and peak load of space heating and cooling demand. This research aims to identify the key parameters associated with the design and operation of office buildings which affect the estimates of space cooling peak load and annual energy demand. Therefore, in this paper, the Morris Elementary Effect (EE) screening method is used on an office building energy model to investigate this.

The research presented in this paper is an initial stage of a larger research project which intends to estimate the

* Corresponding author: vasco.zeferina@manchester.ac.uk 
implications of the effect of future cooling demand of office buildings on power networks due to $\mathrm{CC}$. Being able to predict the timing and profile of future demand is crucial for the long-term planning of energy infrastructure, system operation, and building design. However, there is only a limited amount of literature available addressing the quantification and understanding of the ramifications of CC impacts for building energy demand [11], especially with regard to peak demand for space cooling. Therefore, the outcome of this paper intends to define the implications of different design variables in the peak and annual space cooling demand.

\section{Background and literature review}

\subsection{Sensitivity Analysis}

The sensitivity of building energy model outputs can be explored by using automated parametric simulation which imposes variation on the domain of input parameters. This can enable the analysis of the robustness of the results generated from the execution of a Sensitivity Analysis (SA) [12]. SA investigates the implication of variation in input parameters on the output, these analyses can be categorised into two types, global and local [10]. The local SA explores the sensitivity of individual parameters, so it is a straightforward system; however, it can only analyse a restricted section of the input range. On the other hand, the global SA verifies the implications of several parameters simultaneously [10].

A SA is generally executed in a sequential procedure, starting with the definition of the input parameter to be iterated and the range and distribution to be varied as described by Tian [10]. After this, the sample must be generated with the input parameters to be simulated, which thereby will allow the execution of the simulation in the model. Finally, sensitivity indices of input parameters can be calculated based on the results generated by the simulation of models.

Screening is a particular technique of global SA, it includes the use of a fixing factor, which evaluates the impact of the variation of the model's inputs given a new value to only one factor at each simulation run. Variancebased methods such as SOBOL or FAST, permit to better quantify the full range of variation of each input factor, decompose the variance sources and evaluate the interaction effects among input factors [13]. However, the computational costs of these methods can be prohibitive. The Morris EE method is often used in building energy simulation studies $[14,15]$. It is a simple and easy to implement method that is used to prune input parameters on a complex model, before applying other more complex global SA, namely variance based methods [13]. This method performs a relatively low number of iterations considering a large number of design parameters compared to other methods for global SA. It permits a straightforward interpretation of results, which can give a measure of the overall effect of a parameter on the output, considering also the interaction between parameters.

\subsection{Office simulation parametric studies}

The review of the literature shows that the majority of the studies evaluating the variability in input parameters of building simulations analyse one or several of the following type of parameters: climate conditions, the building form, building fabric, the building occupancy conditions (for example IHG) or the building HVAC system operation. These parametric analyses of building simulations look at different types of outputs, such as the total annual electricity demand [16], overheating risks [17] or annual space cooling demand $[18,19]$.

The parameters identified in the literature which were more correlated to cooling requirements of office buildings are the IHG such as from equipment, lighting and occupants [16,20]. Tian et al. [19] also show that window properties have significant implications for cooling demand. Similarly, the implications of COP and space set-points are also highlighted [21]. CC has significant implications for cooling demand, particularly when using CC projections for 2080 as identified in [17]. However, the effects of input model parameter variance on cooling peak loads are rarely covered in the literature reviewed.

This paper evaluates the effect of different sets of building parameters in the space cooling load requirements of an office building. The parametric study covers analysis of different envelope characteristics, building occupancy patterns, building form, and climate conditions. For this study we have chosen the Morris EE screening method to rank their effect over the space cooling demand. The method is very simple yet is a very effective way to prune the main input factors in a model. Thus, it is indicated to be applied in the analysis over a simplified office model as it is this case. Additionally, the implications of future climate projections will be quantified and the sensitivity of the parameters in these conditions will be compared to the initial conditions.

\section{Methodology}

\subsection{Modelling Framework}

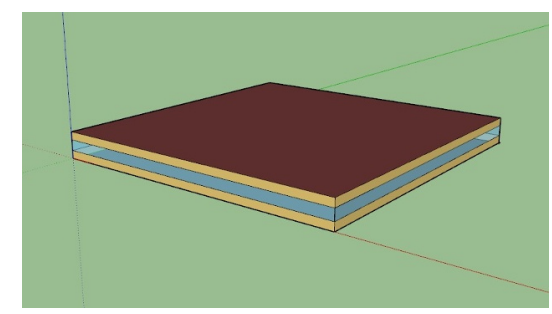

Fig. 1. Standard Model (OpenStudio)

The simulation results of an office building model, shown in Fig. 1, are explored in order to evaluate the sensitivity of space cooling demand to different sets of model parameters. Firstly, the Morris EE screening method is executed in order to identify the input factors with higher predominance in the peak space cooling demand results. Thereafter, the same methodology is executed using 
different climate projections, assessing the implications of future climate on space cooling demand.

\subsection{EnergyPlus Physical Model}

One generic office building energy model was developed in the building performance simulation program EnergyPlus [22], which permits a straightforward parameterisation of main input design parameters. EnergyPlus was chosen because it has been updated and validated continuously over the last 30 years and it is widely used for research due to the confidence in the results produced [23].

The base model of the study is a single floor building, with a gross internal floor area of $1600 \mathrm{~m}^{2}, 40 \mathrm{~m}$ width, $40 \mathrm{~m}$ length, $3.5 \mathrm{~m}$ height, and has a glazing area of $40 \%$ on its external wall. The envelope characteristics of the model were selected based on the benchmark values of ASHRAE 189.1 [24], available in OpenStudio libraries. A summary of the thermal properties of these construction materials is given in Table 1 .

The algorithm chosen for internal calculations of the EnergyPlus engine are the standard provided options. Therefore, the heat balance in the geometries uses the conduction transfer function model, the zone air heat balance uses the third order backward difference model and TARP and DOE-2 are used to calculate inside and outside surface convection coefficients respectively.

The EnergyPlus model utilizes the Ideal HVAC System object, which represents a building operation where cooling or heating loads are supplied in order to meet zone's control specifications. The simulations are then executed at six timesteps per hour, and results are reported at an hourly basis, during a whole simulation year. Space cooling demand is reported as the output results, and different post-process is conducted to obtain analysis at different time-scales. This output refers to the total cooling load of the HVAC system, so including sensible and latent cooling loads.

Table 1. Construction Objects for the EnergyPlus model

\begin{tabular}{|c|c|c|}
\hline & Construction Object & $\begin{array}{l}\text { U-Values } \\
{\left[\mathbf{W} \cdot \mathbf{m}^{-2} \cdot \mathbf{K}^{-1}\right]}\end{array}$ \\
\hline Floor & $\begin{array}{l}\text { ExtSlabCarpet } 4 \text { in Cli. Zone 1- } \\
8\end{array}$ & 0.19 \\
\hline $\begin{array}{c}\text { External } \\
\text { Wall }\end{array}$ & $\begin{array}{l}\text { ASHRAE 189.1-2009 External } \\
\text { Wall }\end{array}$ & 0.45 \\
\hline Windows & $\begin{array}{lc}\text { ASHRAE } & 189.1- \\
\text { 2009ExtWindow Cli. Zone 4-5 }\end{array}$ & 2.5 \\
\hline $\begin{array}{l}\text { External } \\
\text { Roof }\end{array}$ & $\begin{array}{l}\text { ASHRAE 189.1-2009 } \\
\text { ExtRoof IEAD Cli. Zone 2-5 }\end{array}$ & 0.22 \\
\hline
\end{tabular}

\subsection{Base model}

The operation settings of the building model are defined as being uninterrupted, so all the occupancy assumptions are fixed at a single constant value for the whole simulation period. The operational parameters assumptions considered in this analysis are based on generic benchmark information for office buildings given by CIBSE [25] and BRE [5]. For example, total IHG are set at $40 \mathrm{~W} \cdot \mathrm{m}^{-2}$, and the ventilation rate plus the infiltration rate of the building is defined to be 1.6 air changes per hour. The cooling set-point of the zones in the model is set at $24^{\circ} \mathrm{C}$. Table 2 shows the base values of the different variables tested in the simulation.

Korolija et al. [26] defined similar baseline input parameters as used in the base model of the paper, for the UK office buildings archetypal models proposed, namely IHG, infiltration and ventilation rates and cooling setpoints. The latest review of UK regulation for office buildings [27] define maximum values for envelope elements U-values [W. $\mathrm{m}^{-2} \cdot \mathrm{K}^{-1}$ ] as 0.35 for external walls and 2.2 for glazing and 0.25 for roof and ground floor. The base model in this paper presents higher U-values than these legislation limits for glazing and external wall envelopes. However, the range of parameters covered in the SA also include samples that will simulate cases with much lower values than the legislation limits.

\subsection{Parametric study}

The variation considered in the analysis on the model input parameters is shown in Table 2. The analysis presented here has tested the input variation with this range of parameters, accordingly the distribution of conditions used, and it does not intend to represent the statistical representation of the parameters in the current office building stock. Rather, the purpose is to test the sensitivity of the model output results on the foreseeable possible range of the input parameter. Therefore, uniform distribution of these parameters values is considered, with ranges spanning from the minimum and maximum values that are assumed to be plausible to find in office buildings.

The input parameters are grouped into 3 functional categories of building characteristics. The first focuses only on the building envelope (P1-P8), the second focuses on operational parameters (P9-P12) and the third category focuses on building form (P13-P16).

Table 2. Input Parameters

\begin{tabular}{|c|c|c|c|c|}
\hline & & Parameter & Baseline & Distribution \\
\hline \multirow{8}{*}{ 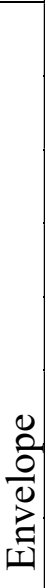 } & P1 & $\begin{array}{l}\text { Thermal } \\
\text { Absorptance }{ }^{1,2}\end{array}$ & $0.9^{1}$ & $\mathrm{U}(0.5 ; 0.96)$ \\
\hline & $\mathbf{P 2}$ & $\begin{array}{l}\text { Solar } \\
\text { Absortance }{ }^{1,2}\end{array}$ & 0.7 & $\mathrm{U}(0.3 ; 0.96)$ \\
\hline & P3 & $\begin{array}{l}\text { Solar Glass } \\
\text { Transmissivity }^{1}\end{array}$ & 0.3311 & $\begin{array}{c}\mathrm{U}(0.15 ; \\
0.38)\end{array}$ \\
\hline & P4 & CP Concrete & $\begin{array}{c}837 \\
\text { J.kg-1 } \cdot \mathrm{K}^{-1}\end{array}$ & $\begin{array}{c}\mathrm{U}(200 ; \\
4000)\end{array}$ \\
\hline & P5 & $\begin{array}{l}\text { Glass } \\
\text { conductivity }\end{array}$ & $\begin{array}{c}0.0133 \\
\text { W. } \mathrm{m}^{-1} \cdot \mathrm{K}^{-1} \\
\end{array}$ & $\begin{array}{c}\mathrm{U}(0.005 ; \\
0.03)\end{array}$ \\
\hline & P6 & $\begin{array}{l}\text { External Wall } \\
\text { insulation }{ }^{1}\end{array}$ & $\begin{array}{c}0.0432 \\
\text { W. } \mathrm{m}^{-1} \cdot \mathrm{K}^{-1}\end{array}$ & $\begin{array}{c}\mathrm{U}(0.01 ; \\
0.065)\end{array}$ \\
\hline & P7 & Roof insulation $^{1}$ & $\begin{array}{c}0.049 \\
\text { W. } \mathrm{m}^{-1} \cdot \mathrm{K}^{-1} \\
\end{array}$ & $\begin{array}{c}\mathrm{U}(0.01 ; \\
0.065)\end{array}$ \\
\hline & P8 & $\begin{array}{l}\text { External } \\
\text { Absorptance }^{1,2}\end{array}$ & 0.92 & $\mathrm{U}(0.5 ; 0.97)$ \\
\hline \multirow{2}{*}{$\begin{array}{l}\text { ত্రు } \\
\text { Оे }\end{array}$} & P9 & Sensible IHG ${ }^{4,5}$ & $\begin{array}{c}40 \\
\text { W.m } \\
-2\end{array}$ & $\mathrm{U}(10 ; 80)$ \\
\hline & P10 & Ventilation Rate $e^{4,5}$ & $\begin{array}{c}0.0015 \\
\mathrm{~m}^{3} \cdot \mathrm{s}^{-1} \cdot \mathrm{m}^{-2}\end{array}$ & $\begin{array}{c}\mathrm{U}(0.0005 ; \\
0.005)\end{array}$ \\
\hline
\end{tabular}




\begin{tabular}{|c|c|c|c|c|}
\hline & P11 & Infiltration Rate Ra $^{4,5}$ & $\begin{array}{c}0.0002 \\
\mathrm{~m}^{3} \cdot \mathrm{s}^{-1} \cdot \mathrm{m}^{-2}\end{array}$ & $\begin{array}{l}\mathrm{U}(0.0001 ; \\
0.001)\end{array}$ \\
\hline & P12 & $\begin{array}{l}\text { Cooling Set- } \\
\text { Point }^{4}\end{array}$ & $24^{\circ} \mathrm{C}$ & $\mathrm{U}(18,26)$ \\
\hline \multirow{4}{*}{ 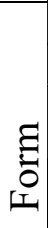 } & P13 & North Rotation & $0^{\circ}$ & $\mathrm{U}(0 ; 180)$ \\
\hline & P14 & Glazing area & $40 \%$ & $\mathrm{U}(5 \% ; 75 \%)$ \\
\hline & P15 & $\begin{array}{l}\text { North Facade / } \\
\text { East Facade ratio }\end{array}$ & 1 & $\mathrm{U}(0.4 ; 9)$ \\
\hline & P16 & $\begin{array}{l}\text { Ratio relative to } \\
\text { base model area }\end{array}$ & 1 & $\mathrm{U}(0.08 ; 25)$ \\
\hline
\end{tabular}

Source: ${ }^{1}[24] ;{ }^{2}[25] ;{ }^{3}\left[28\right.$, p. $\left.{ }^{3} 3-40\right] ;{ }^{4}[26] ;{ }^{5}[5]$

\subsection{Climate}

Manchester was defined as the location of the model and the future test reference year weather files, produced by the PROMETHEUS project [28], were utilized in this simulation procedure. Five files were used, as shown in Table 3, one representing the baseline weather conditions (C5) and four different potential future climate impacts (C1-4). This evaluates the implications of different levels of CC impacts, as these four files consider different level of probabilities $(10 \%, 50 \%$, and $90 \%)$ for the high emission scenario (a1f1) in 2080 and $90 \%$ probability of the medium scenario (a1b) in 2080.

Simulations were executed using the whole annual hourly data contained in these weather files. However, Fig. 2 only shows a comparison of the dry bulb temperature profile of three weather files used, between the days that precede and succeed the day of maximum temperature. This emphasizes the possible level of change during annual extreme warmer periods.

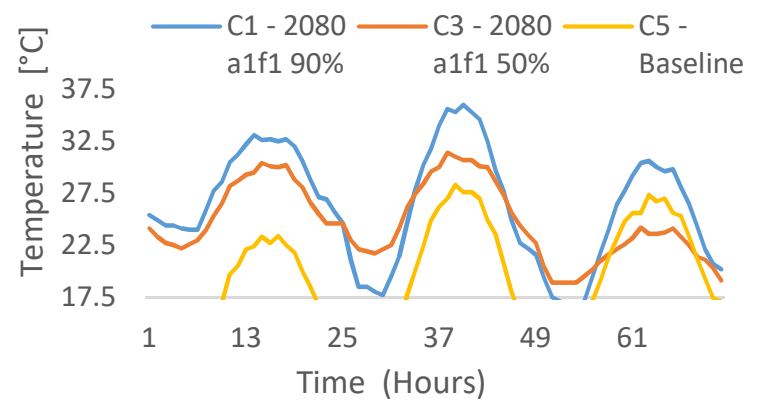

Fig. 2. Dry bulb temperature in a 3 day period, between the days that precede and succeed the day of maximum temperature

In Fig. 2, it can be seen that the dry bulb temperature profile in these future climate projections will be significantly shifted compared to the current baseline weather profile (C5). The annual maximum temperature is expected to reach $37.2^{\circ} \mathrm{C}$ in the worst scenario $(\mathrm{C} 1)$, almost $9^{\circ} \mathrm{C}$ higher than the current baseline maximum dry bulb temperature. Additionally, Table 3 provides a summary of the weather data in terms of annual cooling degree days (CDD) and cooling degree hours (CDH) contained in the 5 climate files used in this analysis. A steep increase (tenfold) in the number of CDDs is predicted within the a1f1 (C1 case) climate projection. Similarly, during the three days period analysed in Fig. 2, the $\mathrm{CDH}$ in scenario $\mathrm{C} 1$ double compared to the baseline period levels (C5). Therefore, the same series of simulations will be conducted with the different weather files to access the implications of the climate in the space cooling demand of the model.

Table 3. Weather data information on climate files utilized

\begin{tabular}{|c|c|c|c|c|}
\hline \multicolumn{2}{|c|}{$\begin{array}{c}\text { Number and file } \\
\text { description }\end{array}$} & $\begin{array}{c}\text { Annual } \\
\text { CDD* }\end{array}$ & $\begin{array}{c}\text { 3 Days } \\
\text { CDH* }\end{array}$ & $\begin{array}{c}\text { Max. } \\
\text { Temp. }\end{array}$ \\
\hline C1 & 2080 a1f1_90\% & 1020 & 813 & 37.2 \\
\hline C2 & 2080 a1b1_90\% & 836 & 767 & 33.3 \\
\hline C3 & 2080 a1f1_50\% & 596 & 703 & 31.4 \\
\hline C4 & 2080 a1f1_10\% & 296 & 415 & 28 \\
\hline C5 & Baseline period & 103 & 337 & 28.3 \\
\hline
\end{tabular}

*CDD and $\mathrm{CDH}$ calculated based on $15^{\circ} \mathrm{C}$ baseline

\subsection{Sensitivity Measures}

Firstly, a sample of 595 different variations of input parameters was created according to the Morris EE method [13], screening individually and sequentially all 16 input variables in a systematic manner, denominated trajectories, for 35 different times. The distribution ranges of each variable are shown in Table 2, and the generation of the input parameter samples was conducted using SIMLAB [29] for the Morris EE method, considering six different input levels for each variable. Thereafter, the sample input parameters were imported into JEPlus [30], and simulations were executed in EnergyPlus. The peak total space cooling demand and annual total space cooling demand for each simulation executed were collected to calculate the Morris screening indices (Equations, 1, 2 and 3) [13]:

$$
\begin{gathered}
\mu_{i}^{*}=\frac{1}{r} \sum_{j=1}^{r}\left|\frac{y\left(x^{(l+1)}\right)-\left(x^{(l)}\right)}{\Delta}\right| \\
E E_{i}^{j}\left(x^{(l)}\right)=\frac{y\left(x^{(l+1)}\right)-\left(x^{(l)}\right)}{\Delta} \\
\sigma_{i}^{2}=\frac{1}{r-1} \sum\left(E E_{i}^{j}-\mu\right)
\end{gathered}
$$

Where:

$$
\begin{array}{cl}
\mu_{i}^{*} & \text { Mean, sensitivity measure } \\
\sigma_{i} & \text { Standard deviation, sensitivity measure } \\
E E_{i}^{j} & \text { Elementary effect relative to factor } i \text { alo } \\
r & \text { trajectory } j \\
j & \text { Total number of trajectories } \\
i & \text { Current trajectory } \\
\Delta & \text { Parameter analysed } \\
& \text { Sampling distance interval }
\end{array}
$$

Based on the screening sensitivity measures results $\left(\mu_{i}{ }^{*}, \sigma_{i}\right)$ the model input parameters are ranked and further analysis of parameter sensitivities are focused on this restricted number of parameters.

\section{Results}


Firstly, the results for space cooling requirements of the standard baseline office building model, defined in the considered standard parameter settings and utilizing the current base climate file are presented. The annual total space cooling demand, in this case, is $38.8 \mathrm{kWh} . \mathrm{m}^{-2}$ of the floor space area and the peak space cooling demand during the simulated year period is $55.2 \mathrm{~W} \cdot \mathrm{m}^{-2}$. CIBSE guide $\mathrm{F}$ [31] states that space cooling requirements to be between 14-41 kWh.m-2.year-1. Abela et al. [6] concluded average peak cooling power in the UK is $50-75 \mathrm{~W} \cdot \mathrm{m}^{-2}$. This peak value is significant behind the rule of thumb for office building cooling plants given in CIBSE guide $\mathrm{F}$ [31], which may be extremely conservative in assumptions for operating conditions.

Table 4. Space cooling requirement for standard office model in the baseline scenario.

\begin{tabular}{|c|c|}
\hline Annual energy demand & Peak demand \\
\hline $38.8 \mathrm{kWh} . \mathrm{m}^{-2}$ & $55.2 \mathrm{~W} . \mathrm{m}^{-2}$ \\
\hline
\end{tabular}

\subsection{Peak cooling demand}

Two sensitivity measures $\left(\sigma, \mu^{*}\right)$ relative to the peak space cooling demand are calculated for each input parameter of the model. In Fig. 3, the Morris sensitivity measures relative to the peak space cooling demand of the office model are presented. Peak space cooling demand is most sensitive to Parameter 9 - IHG, closely followed by the Parameter 12 - cooling set-point, then by Parameter 10 ventilation rate and finally by the Parameter 16 - indexed relative to the base model area. Glazing ratio (P14), Infiltration rate (P11) and North-East facade ratio (P15) show much lower sensitivity for the peak demand than parameters listed above; however, the sensitivity measures are still noticeable from the remaining parameters. All the remaining input parameters show much smaller effect, as they can be seen in the bottom left of the plot, with reduced values of the sensitivity measures $\left(\sigma, \mu^{*}\right)$.

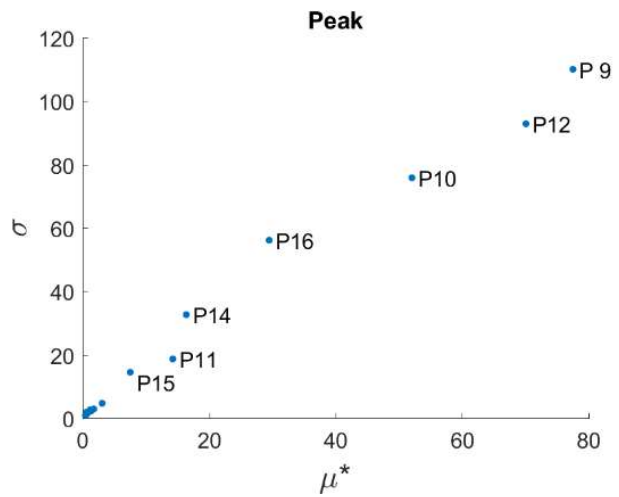

Fig. 3. Morris EE indices for peak cooling load

\subsection{Annual space cooling demand}

The EE sensitivity measures of the building model relative to the annual space cooling demand are presented in Fig. 4. Regarding this simulation output, IHG (P9) is the parameter with the greatest sensitivity, almost doubling the mean sensitivity measure for ventilation rate
(P10) and cooling set-point (P12). Parameter 16 and 11 present sensitivity measures values significantly smaller than the previous parameters, but clearly distinguishable from remaining parameters at the bottom left of figure 4 with much lower values of the sensitivity measures $\left(\sigma, \mu^{*}\right)$.

It is relevant to focus on the significantly larger value of the sensitivity measures presented relative to annual space cooling demand than for peak demand. Additionally, the total variation of the outputs (annual and peak) in the whole Morris EE analysis is presented in Table 5. Both of the sensitivity measures Fig. 3 and Fig. 4 and the extreme variation of the output (Table 5) in the sample simulated show the larger variability of the annual demand than the peak space cooling demand.

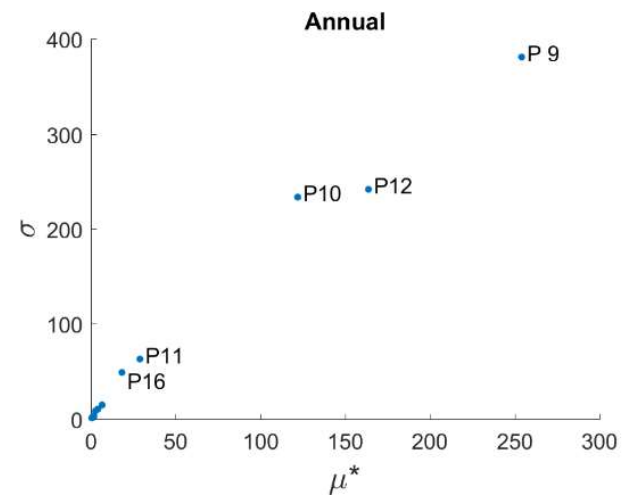

Fig. 4. Morris EE indices for annual cooling energy demand

Table 5, Output variation of the simulation sample used in the Morris EE analysis

\begin{tabular}{|c|c|c|c|}
\hline & Min. & Std. & Max. \\
\hline $\begin{array}{c}\text { Annual } \\
{\left[\text { kWh.m- }{ }^{2}\right]}\end{array}$ & $\begin{array}{c}0.04 \\
(-99.9 \%)\end{array}$ & 38.8 & $\begin{array}{c}563.2 \\
(1352 \%)\end{array}$ \\
\hline $\begin{array}{c}\text { Peak } \\
{[\text { W.m }}\end{array}$-2 $\left.^{-2}\right]$ & $\begin{array}{c}6.72 \\
(-88 \%)\end{array}$ & 55.2 & $\begin{array}{c}209.5 \\
(280 \%)\end{array}$ \\
\hline
\end{tabular}

\subsection{Climate conditions}

The simulation results of the standard parameterisation of the office building model, defined in Table 2, considering different climate conditions are presented in Table 6 . The simulation results indicate that future climate projections may increase the annual space cooling requirements by $287 \%$, for the most pessimistic CC scenario (C1). In the same climate scenario, the peak space cooling demand is increased by $61 \%$. In the least severe future climate scenario considered (C4), the annual space cooling requirement increases $76 \%$; however, the peak is only $8 \%$ higher than the value in the baseline scenario (C5).

Table 6. Base model output evolution considering the different climate scenarios

\begin{tabular}{|l|c|c|}
\hline Climate Projection & $\begin{array}{c}\text { Annual } \\
{\left[\mathrm{kWh} . \mathrm{m}^{-2}\right]}\end{array}$ & $\begin{array}{c}\text { Peak } \\
{\left[\mathrm{W} . \mathrm{m}^{-2}\right]}\end{array}$ \\
\hline (C1) 2080 a1f1 90\% & $150.0(287 \%)$ & $88.6(61 \%)$ \\
\hline (C2) 2080 a1b 90\% & $130.0(235 \%)$ & $85.6(55 \%)$ \\
\hline (C3) 2080 a1f1 50\% & $104.5(169 \%)$ & $78.6(42 \%)$ \\
\hline (C4) 2080 a1f1 10\% & $68.3(76 \%)$ & $59.9(8 \%)$ \\
\hline (C5) Baseline & 38.8 & 55.2 \\
\hline
\end{tabular}


In Fig. 5 and Fig. 6 a comparison of the sensitivity measures relative to both outputs (Peak and Annual demand, respectively) is presented, considering the values achieved on the baseline climate scenario (C5) and for the most severe climate conditions (C1). The peak space cooling demand in a more severe climate, such as $\mathrm{C} 1$, becomes more sensitive than previously due to Parameter 10 , as the sensitivity measure $\mu^{*}$ increases by almost $153 \%$. Similarly, parameters 11 and 16 present significantly larger sensitivity measures, $177 \%$ and $81 \%$ respectively. On the other hand, the sensitivity of the peak demand is not as much changed due to 9 and 12, once sensitivities are only increased by $7 \%$ and $20 \%$, respectively.

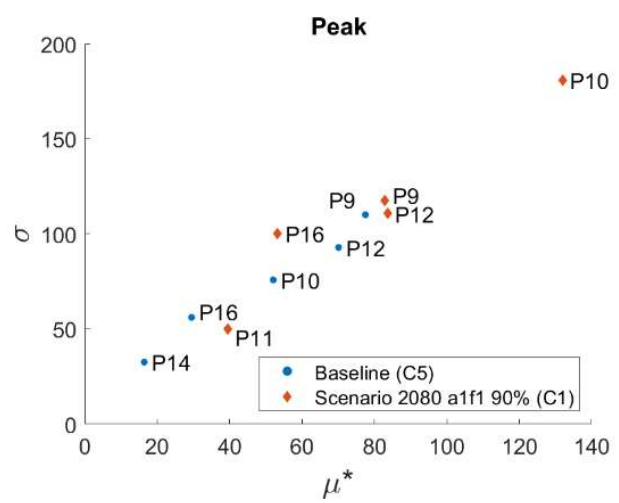

Fig. 5. Sensitivity measures progression of main parameters for peak demand relative to the climate

Relative to the annual space cooling demand, presented in Fig. 6, the output becomes less sensitive in future climate scenarios (C1) regarding several parameters. The mean sensitivity measure, $\mu^{*}$, for parameter 10 and 11 decrease $41 \%$ and $22 \%$ respectively. On the other hand, the sensitivity measures for parameter 9 and 12 are increased by $84 \%$ and $106 \%$ respectively. Therefore, these two parameters continue to assume the largest sensitivity in climate conditions such as in $\mathrm{C} 1$.

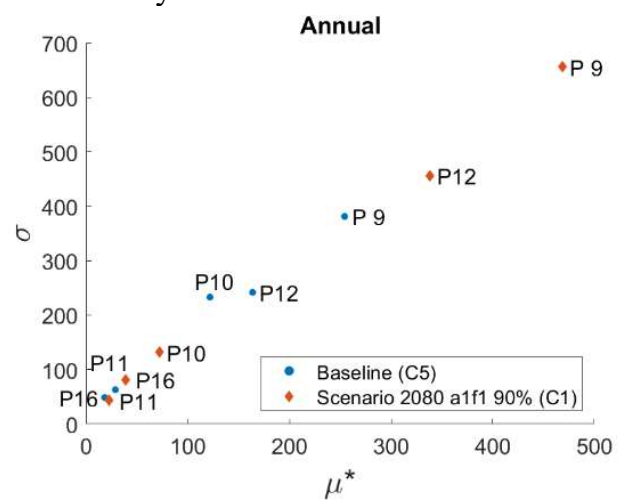

Fig. 6. Sensitivity measures progression of main parameters for annual demand relative to the climate

\section{Discussion}

The validity of the modelling assumptions made for the purpose of this study were initially checked, comparing the output results of the base input model parameters, presented in Table 4, to the benchmark data of typical office buildings in the UK. Thereafter, it is considered that the baseline of the SA is reliable, ensuring the plausibility of the possible findings of the sensitivity procedure proposed.

The clearest finding of the SA conducted is that annual space cooling demand is significantly more sensitive than peak space cooling demand to design parameter variations. The spectrum of variation is around five times larger for the annual space cooling demand than to the peak space cooling in the set of simulations executed. Similarly, the magnitude of the sensitivity measures relative to the annual output is superior to the verified for the peak space cooling demand. Jenkins et al. [8] have similar level of relationship between the change in peak and annual cooling loads for future CC scenarios.

The analysis enables the user to clearly distinguish the implications of 5 input parameters relative to the annual and peak space cooling demand of the model. The sensitivity measures of the parameters both for peak and annual space cooling demand clearly show that the IHG (P9), the control set-point (P12), the ventilation rate (P10), infiltration rate (P11) and the space floor index (P16) are the parameters that influence the most the variability of these outputs.

Both for annual space cooling demand and peak space cooling demand, the IHG (P9), the control cooling setpoint $(\mathrm{P} 12)$ and the ventilation rate $(\mathrm{P} 10)$ present the largest implications. This is expected to be significantly altered in future climate scenarios. Ventilation (P10) and infiltration rates $(\mathrm{P} 11)$ are expected to have larger sensitivity on peak demand for future climates than have been shown in current climate. However, for future annual space cooling demand, the same parameters present smaller sensitivity measures than compared to current scenario. Therefore, ventilation rate (P10) will present the largest implication for peak space cooling demand and, IHG (P9) and cooling set-point (P12) have the largest sensitivity for annual cooling demand.

Table 7 presents a measure of local sensitivities of input parameters for the base standard model, given in Table 2. These local sensitivities are the ratio between the maximum and output result, on a set of simulations that alters individually and only a single parameter over the whole admissible input range. A large ratio imply a significant variation of the output considering only the change of that parameter. Comparing the relative grade of IHG parameter (P9) to other parameters on local sensitivity results, and among Morris EE sensitivity measures values, it is possible to identify substantial discrepancies. This indicates a correlation effect of input parameters that exacerbate or minimize the sensitivity of the model output relative to a parameter in a global analysis. Therefore, significant differences between the grades of sensitivity of a model relative to each input parameter can exist between local and global SA.

Table 7. - Ratio of maximum/minimum output results with local (individual) variation of model input parameters

\begin{tabular}{|c|c|c|}
\hline Par. & Peak & Annual \\
\hline P9 & 4.57 & 451.26 \\
\hline P12 & 1.84 & 12.15 \\
\hline P10 & 1.73 & 13.06 \\
\hline
\end{tabular}




\begin{tabular}{|l|l|l|}
\hline P16 & 1.53 & 1.04 \\
\hline P14 & 1.21 & 1.21 \\
\hline P11 & 1.18 & 2.41 \\
\hline
\end{tabular}

The change in IHG parameterisation (P9) has by far the largest impact for the space cooling demand of the base model, as shown in Table 7. However, the Morris EE sensitivity measures show that the change on IHG in combination with other parameters, reduce its relative importance relative to other parameters. For example in Fig. 3, the cooling set-point (P12) presents almost as large sensitivity on peak space cooling demand as IHG parameter, besides the much lower local sensitivity presented in Table 7. This emphasizes the importance of global SA, exposing the risks of creating misconceptions by only utilizing local sensitivity of parameters.

\subsection{Climate}

The analysis of the sensitivity measures according to different climate projections indicates that there is significant collinearity between the input parameters of the model and the type of weather or climate conditions considered. It is concluded that for future climates, the annual space cooling loads will be even more sensitive to IHG (P9) and control cooling set-points (P12). The peak space cooling demand will be significantly more sensitive to the ventilation rate $(\mathrm{P} 10)$. Additionally, the sensitivity to IHG and cooling set-point are only slightly higher, so the ventilation rate will present the largest sensitivity to the peak demand in the future.

The predicted change in annual and peak space cooling demand is substantial, for all of the climate scenarios considered, being $76 \%$ to $287 \%$ larger for annual and $8 \%$ to $61 \%$ larger for peak demand. This level of change is in accordance with previous research on the implications of CC for UK office buildings [18]. However, the sensitivity of the model to the alteration of input parameters according to the Morris EE method for the baseline climate, have shown levels of change five times larger than the change verified analysing the different climate scenarios on the base model. Jenkins et al. [8] have also shown that design mitigation measures can completely overcome the impacts of CC for annual cooling requirements. However, there is little understanding of how design changes rather than mitigating, could reinforce or even exacerbate the scale of further demand, especially peak cooling demand.

The research findings of this paper should be used with caution, as there are risks of extrapolating the findings outside the simulation conditions tested. The research was conducted using a unique physical model only looking on the space cooling demand. Therefore, it does not consider the interaction of the HVAC system, of the building envelope and consequential effects on the final energy demand for the HVAC system. Similarly, in this paper, only EE methods were used to assess the global sensitivity of the model. Sensitivity results from additional alternative methods are important to reinforce the confidence and the coherence of the modelling approach, as emphasized by Clarke and Hensen [32].
As the analysis is conducted on a single floor building, with simplified geometries and configurations, the extrapolations of these findings to more complex buildings should be made carefully, namely to building configurations with multiple floors and significantly different configurations. Moreover, the simulation set was performed using a unique algorithm for the model calculation. It is known that some of the calculation assumptions on heat transfer processes, such as convection, radiation, conduction or heat balances may have implications for the results, as assessed in [33,34].

Future research work should analyse the implications of multi-storey buildings models, and analyse further the implications of the collinearity of parameters with different sensitivity methods. It would be important to assess the effect of the ground effect in the results, not only by comparing the demand with models with multiple floors, but also evaluating the impact of different assumptions for the heat ground energy transfer.

\section{Conclusions}

This paper has enabled the quantification and ranking of the implications of the different input parameters in the space cooling demand of office buildings. Moreover, this has enabled the quantification of the potential impacts of $\mathrm{CC}$ on the space cooling demand of offices, and how the sensitivity of the different parameters will evolve among the different climate projections.

Firstly, the implications for annual space cooling demand will be significantly larger than for the peak demand. On average, the rate of increase for annual demand is five times larger than for the peak demand. Secondly, it is assessed that future climates, by 2080 s, may cause up to $287 \%$ and $61 \%$ increase over the current baseline scenario, respectively for annual and peak space cooling demand. However, the variability of the space cooling demand is much larger (up to five times) only due to changes in the input parameter assumptions. This reinforces the importance of attentively assessing the different options for operation and design, during the building design project phase.

Finally, it is possible to conclude that IHG (P9) is the input parameter with the largest implications for the annual space cooling demand, being followed by the control set-point temperature (P12) and the ventilation rate (P10). Similarly, for the peak demand, these parameters are ranked in the same order of importance using current scenarios. Additionally, it is concluded that in future climate scenarios, the sensitivity on peak demand relative to current baseline climate scenario, relative to the main input parameters will be larger, particularly the ventilation rate $(\mathrm{P} 10)$. However, for the annual demand, the IHG (P9) and cooling set-point (P12) will have much larger implications whilst ventilation (P10) and infiltration rates (P11) will have smaller influences.

The research findings of this paper should be used with caution, as the simulation conditions proposed by the analysis present several limitations. For example, using a unique single floor physical model does not enable 
analysis of the final energy demand of the HVAC system. In addition, the analysis does not explore the effect over multiple-storey buildings, the effect of different ground floor conditions or different calculation algorithm assumptions. Similarly, only using the EE method does not enable evaluation of the collinearity effect of the parameters, and comparison of sensitivity levels using other global methods. Finally, the climate change scenario considered to compare the change parameters sensitivity is extreme, and may be unlikely to occur. Therefore, the plausibility of this scenario to occur is small, and it should not be considered as the estimation of a likely future system performance.

In the future, it is intended to extend the analysis of the CC impacts to archetype models that also analyse the implications for the final energy demand for the cooling demand of buildings, considering several different HVAC system options. Additionally, the implications of different algorithm calculation methods will be evaluated, together with further design and operation parameters important for the final energy and space cooling demand of office buildings. These may include alternative cooling methods and measures to minimise cooling e.g. solar shading or passive cooling strategies. Different global SA methods will be used to further assess the coherence of the analysis.

\section{Simulation Data and Model}

The necessary data and models to execute the analysis presented are available at:

https://github.com/vascozeferina/CLIMA2019

\section{References}

[1] G.J. Jenkins, J.M. Murphy, D.M.H. Sexton, J.A. Lowe, P. Jones, C.G. Kilsby, UK Climate Projections: UKCP09, (2009).

[2] R. Gupta, M. Gregg, K. Williams, Build. Serv. Eng. Res. Technol. 36 ,196-220, (2015).

[3] M. Kolokotroni, X. Ren, M. Davies, A. Mavrogianni, En. Build. 47 ,302-311, (2012).

[4] S.N. Chandramowli, F.A. Felder, Sust. En. Tec. Ass. $5,62-74,(2014)$.

[5] Building Research Energy Conservation Unit (BRECSU), Energy Consumption Guide 019: Energy Use in Office, (2003).

[6] A. Abela, L. Hamilton, R. Hitchin, C. Pout, A. Lewry, Study on Energy Use by Air- Conditioning, (2016).

[7] D.H.C. Chow, G.J. Levermore, Build. Ser. Eng. Research \& Technology 31, 307-323, (2010).

[8] D.P. Jenkins, M. Gul, S. Patidar, Energy Build. 66 ,57-65, (2013).

[9] C.J. Hopfe, J.L.M. Hensen, Energy Build. 43 ,27982805, (2011).

[10] W. Tian, Renew. Sustain. Energy Rev. 20 ,411-419, (2013).

[11] F.R. Wood, D. Calverley, S. Glynn, S. Mander, C. Walsh, J. Kuriakose, F. Hill, M. Roeder, Infrastruct. Asset Manag. 2 ,107-119, (2015).
[12] J.A. Clarke, J. Build. Perform. Simul. 8 ,39-43, (2015).

[13] A. Saltelli, M. Ratto, F. Campolongo, J. Cariboni, D. Gatelli, Global Sensitivity Analysis. The Primer, (2008).

[14] P. Heiselberg, H. Brohus, A. Hesselholt, H. Rasmussen, E. Seinre, S. Thomas, Renew. Energy. $34,2030-2036,(2009)$.

[15] Y. Heo, R. Choudhary, G.A. Augenbroe, Energy Build. 47 ,550-560, (2012).

[16] J.C. Lam, K.K.W.W. Wan, K.L.L. Cheung, L. Yang, Energy Build. 40 ,828-836, (2008).

[17] P. De Wilde, W. Tian, Energy Build. 42 ,16741684, (2010).

[18] W. Tian, P. De Wilde, J. Build. Perform. Simul. 4 ,105-124, (2011).

[19] W. Tian, J. Song, Z. Li, P. de Wilde, Appl. Energy. $135,320-328,(2014)$.

[20] P. de Wilde, W. Tian, Build. Simul. 2 ,157-174, (2009).

[21] H. Janssen, Reliab. Eng. Syst. Saf. 109 ,123-132, (2013).

[22] U.S. Department of Energy, EnergyPlus version 8.9, https://energyplus.net/, (2018).

[23] D.B. Crawley, J.W. Hand, M.M. Kummert, B.T. Griffith, Build. Environ. 43 ,661-673, (2008).

[24] ASHRAE, Standard 189.1-2009: Standard for the Design of High-Performance Green Buildings, (2009).

[25] CIBSE, CIBSE Guide A: Environmental Design, (2016).

[26] I. Korolija, L. Marjanovic-Halburd, Y. Zhang, V.I. Hanby, En. And Build. 60 ,152-162, (2013).

[27] HM Government, Conserv. Fuel Power. L2A ,1-66, (2010).

[28] M. Eames, T. Kershaw, D. Coley, Build. Serv. Eng. Res. Technol. 32 ,127-142, (2011).

[29] S. Tarantola, W. Becker, SIMLAB Software for Uncertainty and Sensitivity Analysis, in: Handb. Uncertain. Quantif., Springer International Publishing, Cham, pp. 1979-1999, (2017).

[30] Y. Zhang, I. Korolija, Jeplus.Org. (2015).

[31] CIBSE, CIBSE Guide F - Energy efficiency in buildings, CIBSE, (2012).

[32] J.A. Clarke, J.L.M. Hensen, Build. Environ. 91 ,294-306, (2015).

[33] G. Petrou, A. Mavrogianni, P. Symonds, I. Korolija, A. Mylona, R. Raslan, D. Virk, M. Davies, 4th BSO Conference,423-429, (2018).

[34] A. Prada, F. Cappelletti, P. Baggio, A. Gasparella, Energy Build. 71 ,53-60, (2014). 